\title{
Positive Effects of Spray-Dried Streptococcus thermophilus on Healing of Second-Degree Burn Wounds in Wistar Rats
}

Amir Abbas Barzegari (PhD) Department of Biology, Faculty of Basic Science, University of Maragheh, Maragheh, East Azerbaijan Province, Iran

Masoud Hashemzaei (MSc) Department of Biology, Faculty of Basic Science, University of Maragheh, Maragheh, East Azerbaijan Province, Iran

Ali-Reza Alihemmati (PhD)

Department of Histology and Embryology, Tabriz University of Medical Sciences, Tabriz, Iran

Corresponding author: Ali-Reza Alihemmati

Email: hematti@yahoo.com

Tel: +984133342086

Address: Associate Professor of Anatomical Sciences, Department of Histology and Embryology, Tabriz University of Medical Sciences,

Tabriz, Iran

Received: 08 Oct 2018

Revised: 09 Dec 2018

Accepted: 31 Dec 2018

\section{(c) (1) (3)}

This work is licensed under a Creative Commons Attribution 4.0 License.

\begin{abstract}
Background and Objectives: Current medications used for the treatment of burn wounds have some side effects and disadvantages. 0ral or topical administration of probiotic bacteria is thought to be useful for treatment of skin disorders. The aim of this study was to evaluate effects of spray-dried Streptococcus thermophilus on healing of second-degree burn wounds.

Methods: After induction of second-degree burn on back of 00 male Wistar rats, the animals were randomly allocated to negative control (no treatment), first vehicle control (treatment with Eucerin), second vehicle control (treatment with skim milk) and experimental (treatment with bacterial ointment) groups. Wound healing rate (percent) and histopathological parameters of wound samples were evaluated on post-burn days 1, 3, 7 and 14 .

Results: 0 n days 3 and 7 , macroscopic results showed that the healing rate was significantly higher in the experimental group compared to the control groups. Histopathological analysis of wound samples showed increased fibroblastic migration, collagen formation and re-epithelialization in the wounds treated with probiotic bacteria compared with the wounds of control groups.

Conclusion: 0ur results indicate that the topical use of spray-dried $S$. thermophilus could be useful for the treatment of burn wounds.

Keywords: Streptococcus thermophilus; Probiotics; Burns; Wound Healing; Rats.
\end{abstract}

This paper should be cited as: Barzegari AA, Hashemzaei M, Alihemmati AR [Positive Effects of Spray-Dried Streptococcus thermophilus on Healing of Second-Degree Burn Wounds in Wistar Rats]. mljgoums. 2019; 13(2):23-29 


\section{INTRODUCTION}

In spite of the fact that burns are preventable injuries (1), epidemiological studies indicate that the incidence of burns is still relatively high, especially in developing countries (2). Burn wounds are classified into first-, second- and third-degree injuries (3). Because the wound area is prone to infections, topical or systemic antibiotics are frequently used for burn management (4), which may be associated with undesirable side effects and antibiotic resistance $(5,6)$. Nowadays, probiotics are proposed as suitable alternatives to antibiotics for treatment of diseases (7). A probiotic is defined as a viable microorganism, especially bacteria, that can exert beneficial effects after being taken by the host (8). New research indicates that oral or topical use of bacterial probiotics may be effective in treatment of skin disorders (9-13). Previous studies show that local application of Streptococcus thermophilus on the skin may increase the skin's ceramide level in the epidermis, which may be useful in the treatment of atopic dermatitis (14). Moreover, it has been shown that the use of topical ceramide by itself can accelerate the wound healing process (15). Therefore, it may be concluded that the use of $S$. thermophilus on the wounds may increase the speed of wound healing.

One of the low-cost methods for long-term preservation of bacteria is spray-drying (16). Previous studies indicate that spray-dried bacteria including some lactic acid bacteria maintain their antagonistic activity against opportunistic bacteria that may infect the wounds, such as Staphylococcus aureus (17). In addition, spray-drying of lactic acid bacteria has no effect on their bacitracin production potential $(17,18)$. Studies have investigated the effects of topical use of free cultures of probiotic bacteria on wound healing $(19,20)$, but no study has yet evaluated the effects of topical spray-dried lactic acid bacteria on this process. Thus, the purpose of the present research was to evaluate the effects of spraydried S. thermophilus on the wound healing process in a rat model of second-degree burn wound.

\section{MATERIALS AND METHODS}

Male Wistar rats were obtained from the Pasture Institute of Tehran, Iran. Before starting the experiments, the rats were kept In a standard room, under 12/12 light-dark cycle and temperature of about $22{ }^{\circ} \mathrm{C}$. The animals had ad libitum access to food and water at all times. All experimental procedures were approved by the ethics committee of University of Maragheh (approval code: 96083155). A standard method used by Pereira et al. was adopted for induction of seconddegree burn wounds (21). Briefly, the rats received intraperitoneal anesthetic mixture of $80 \mathrm{mg} / \mathrm{kg}$ ketamine and $10 \mathrm{mg} / \mathrm{kg}$ xylazine (both purchased from Alfasan Company, Netherlands).

Hair of back skin, near the forelimbs, was removed with a clipper. Then, the hairless area was antisepticised and base of a solid aluminum rod (diameter $=10 \mathrm{~mm}$ ) pre-exposed to temperature of $96{ }^{\circ} \mathrm{C}$ was placed on the area for 15 seconds. Next, the rats were placed in separate cages and received buprenorphine, which has relatively long analgesic effects (22).

Spray-dried probiotic $S$. thermophiles (ATCC 19258) was obtained from Zisttakhmir Corporation (Tehran, Iran) in a powder containing $10^{10}-10^{11} \mathrm{CFU}$ of the bacteria per gram sample.

The experiments were conducted in 1-, 3-, 7and 14-day periods. On the day of burn induction (day 0), the rats were randomly divided into 16 groups of 5. Four groups (subgroups 1, 2, 3, 4) were assigned as negative controls and received no treatment; they were euthanized after 1, 3, 7 and 14 days post-burn, respectively.

Four groups (subgroups 5, 6, 7, 8) were assigned to first vehicle controls and received Eucerin every day for 1, 3, 7 and 14 days, respectively. Four groups (subgroups 9, 10, 11, 12) were assigned to the second vehicle controls and received daily skim milk for the same period as the first vehicle controls did. The remaining four groups of rats (the experimental groups) received the bacterial powder in Eucerin every day just like the time schedule of vehicle controls treatment.

Assessment of the wound healing process was made by calculating the wound healing percentage on days $1,3,7$ and 14 of the experiments and by histopathological analysis of the wound areas using wound samples on the same days.

The following formula was used to calculate the healing percentage: 
Wound healing percentage on day $x$

$$
\begin{aligned}
& =(1 \\
& \left.-\frac{\text { wound area on day } x}{\text { wound area on day } 1}\right) \\
& \times 100
\end{aligned}
$$

For evaluation of histological parameters as measures of wound healing, biopsy specimens of the wound tissues collected on days 1, 3, 7 and 14 were fixed, processed, embedded in paraffin blocks and sectioned. The tissue sections $(5 \mu \mathrm{m}$ thick) were stained with hematoxylin and eosin. The parameters analyzed for the wound healing assessment included inflammatory response, fibroblast migration, formation and orientation of collagen fibers and re-epithelialization. A histologist, blind to the conditions of the experiments, scored the parameters by averaging the intensity of the above parameters in five visual field of each slide: () absence, $(+)$ mild presence, $(++)$ moderate presence and (+++) strong presence (21).

SPSS software (version 19) was used for statistical analysis of quantitative data. Factorial ANOVA was used for determining possible interactions between time and treatments on the healing percentage on different days. LSD post hoc test was done for significant results. Data were expressed as mean \pm SEM.

\section{RESULTS}

On the third day, the wound healing rate (\%) of the experimental group was significantly higher than that of the control groups except for the second vehicle control group. On day 7, the wound healing rate in the experimental group was significantly higher than in all control groups. On day 14, the wound healing rate was significantly greater in the experimental group compared to both vehicle groups (Figure 1).

Microscopic evaluation of the wound area on the first post-burn day showed the disruption of epidermis, presence of cavities in damaged tissues and denaturation of collagen fibers. Altogether, on day one, the structural damages observed in all groups were almost identical (Figure 2). On the third day, the inflammatory response in the experimental groups reduced compared to both vehicles and negative control groups (Figure 3 and Table 1). On the next day, the greatest reduction in the inflammatory response was observed in the experimental group (Figures 4 and 5). On postburn days 7 and 14, the experimental group had the highest rate of collagen fiber formation, and the fiber had more regular patterns than other groups (Figures 4 and 5). Finally, the rate of re-epithelialization in the experimental group was higher than in the

\begin{tabular}{|c|c|c|c|c|c|}
\hline Group & $\overline{\text { Day }}$ & $\begin{array}{c}\text { Inflammatory } \\
\text { response }\end{array}$ & $\begin{array}{l}\text { Fibroblast } \\
\text { migration }\end{array}$ & $\begin{array}{c}\text { Collagen } \\
\text { formation }\end{array}$ & Epithelialization \\
\hline \multirow{4}{*}{ Negative control } & $1^{\text {st }}$ & ++ & - & - & - \\
\hline & $3^{\text {rd }}$ & +++ & + & - & + \\
\hline & $7^{\text {th }}$ & ++ & ++ & + & + \\
\hline & $14^{\text {th }}$ & + & ++ & ++ & ++ \\
\hline \multirow{4}{*}{$\begin{array}{c}\text { First } \\
\text { vehicle control }\end{array}$} & $1^{\text {st }}$ & ++ & - & - & - \\
\hline & $3^{\text {rd }}$ & +++ & + & - & + \\
\hline & $7^{\text {th }}$ & ++ & ++ & + & + \\
\hline & $14^{\text {th }}$ & ++ & ++ & ++ & ++ \\
\hline \multirow{2}{*}{$\begin{array}{c}\text { Second } \\
\text { vehicle control }\end{array}$} & $\mathbf{1}^{\mathrm{st}}$ & ++ & - & - & - \\
\hline & $3^{\text {rd }}$ & +++ & + & - & + \\
\hline \multirow{6}{*}{ Experimental } & $7^{\text {th }}$ & ++ & ++ & + & + \\
\hline & $14^{\text {th }}$ & ++ & ++ & ++ & ++ \\
\hline & $1^{\text {st }}$ & ++ & - & - & - \\
\hline & $3^{\text {rd }}$ & ++ & + & - & + \\
\hline & $7^{\text {th }}$ & + & +++ & ++ & ++ \\
\hline & $14^{\text {th }}$ & + & + & +++ & +++ \\
\hline
\end{tabular}
control groups on day 14 (Figure 5).

Table 1- Histopathological parameters of wound areas on post-burn days 1, 3, 7 and 14. 
Figure 1- Wound healing rate (\%) in the control and experimental groups on days 1, 3, 7 and 14.

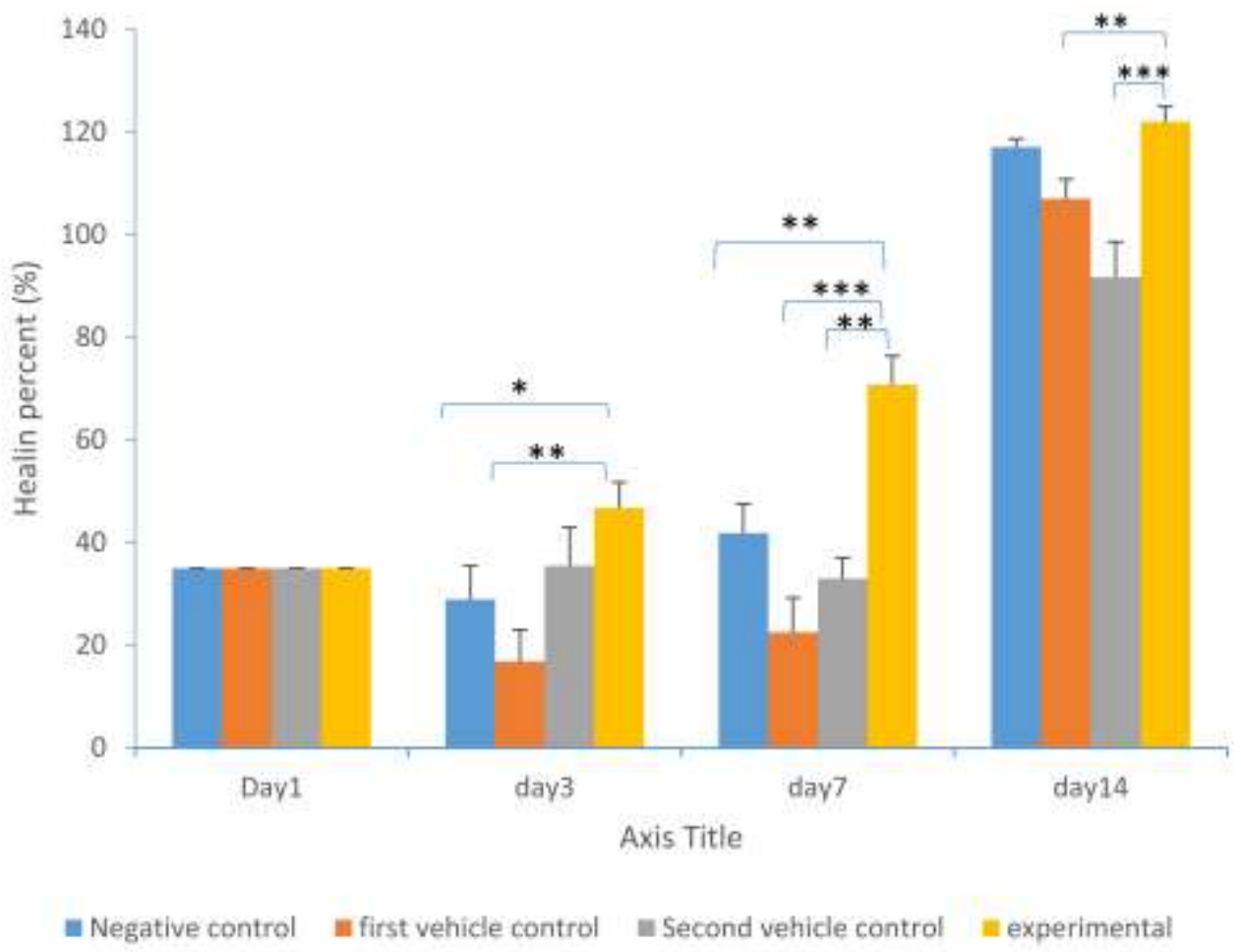

Figure 2- Microscopic images of the wound tissue samples on the first day of the experiments. (a): negative control, (b): first vehicle control, (c): second vehicle control and (d) the experimental groups. The arrowheads show the disruption of epidermis by heat. The arrows show thick collagen fibers with distorted structure caused by the high temperature. The star represents the cavities created in the damaged tissues. The images were captured at 400x magnification.
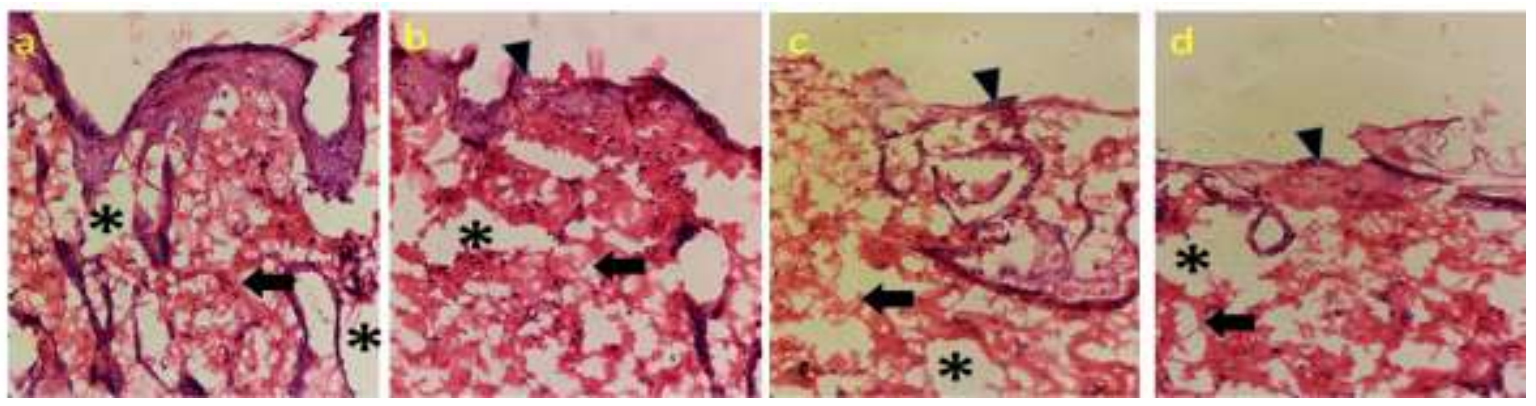

Figure 3- Images of tissue sections of the wound samples on the third day. There was a wide infiltration of inflammatory cells to the wound area. The density of inflammatory cells in the experimental group (d) was lower than in the control groups (a, b and c). Yellow arrows show inflammatory cells. The images were captured at 400x magnification.
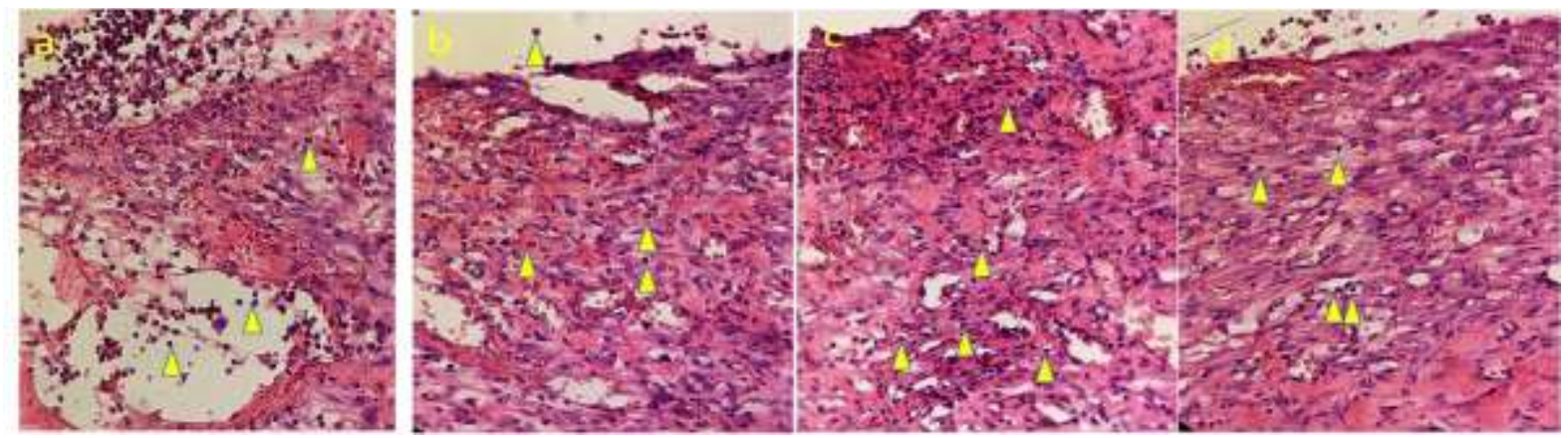
Figure 4- Images of tissue sections of the wound samples on day 7. The density of inflammatory cells (yellow arrowheads) in the tissue sections of the experimental group (d) was still lower than that of the control groups (a, b and c). In addition, in the experimental groups, collagen fibers had a more regular structure and arrangement compared with the control groups. More cavities can be observed in the dermis layer of samples from the negative and positive control groups $(\mathrm{a}, \mathrm{b}$, and $\mathrm{c})$ compared to the experimental group. Two-way arrows show the formation of epidermis in all groups. Blue arrows and black arrows represent fibroblasts and collagen fibers, respectively. The images were captured at 400x magnification
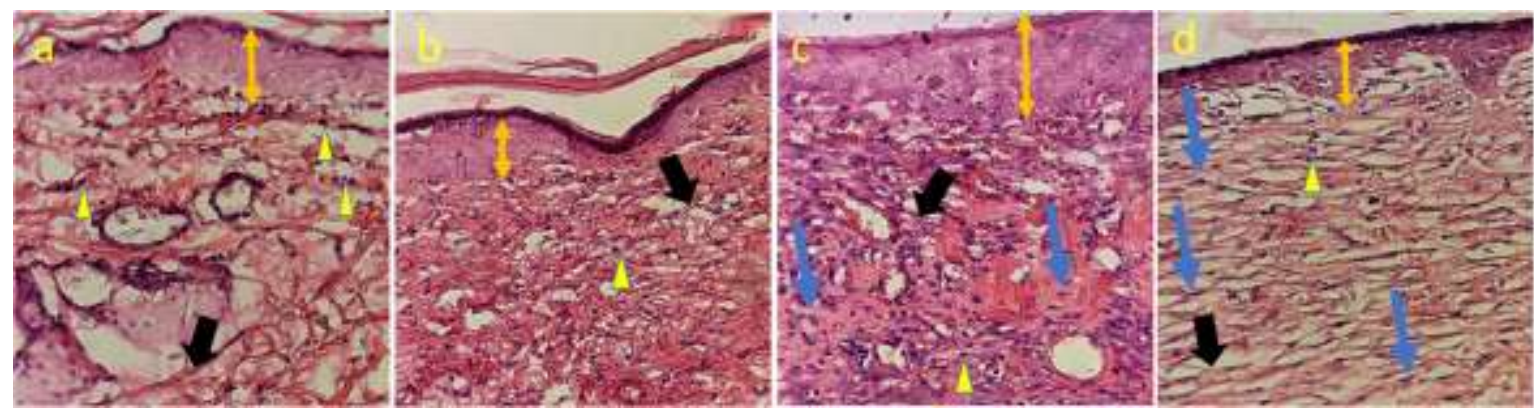

Figure 5- Images of tissue sections of the wound samples on day 14. The epidermis (bidirectional arrows) in the experimental group (d) was thicker than in other groups $(a, b$ and $c)$. In the experimental group, inflammatory cells with circular and dens colored nuclei were less scattered. In this group, the collagen fibers were also thicker and had a more regular pattern compared to other groups. The images were captured at 400x magnification
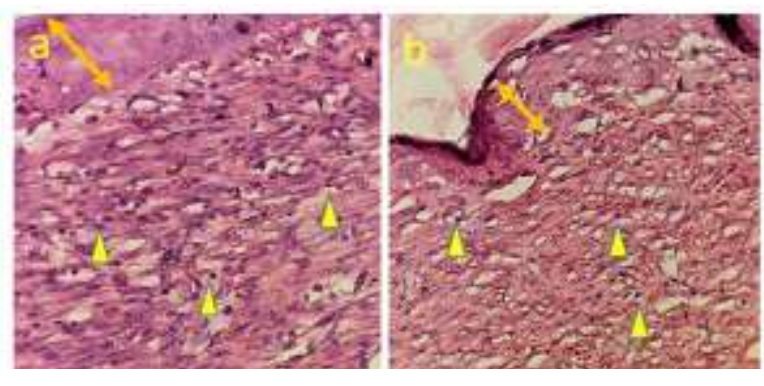
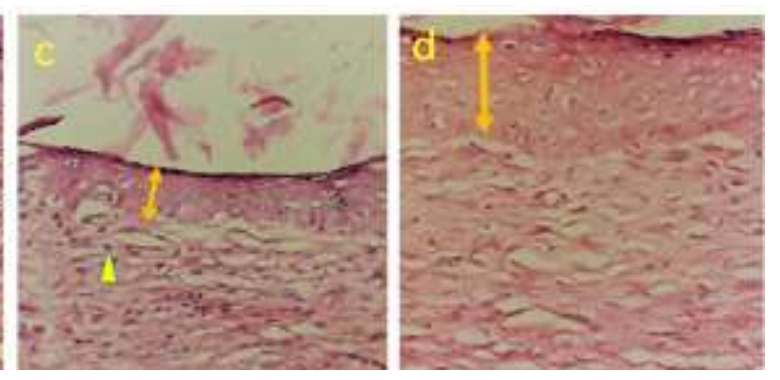

\section{DISCUSSION}

In the second- and third-degree burns, the healing process involves inflammatory response, proliferation and remodeling phases (23). Our experimental results showed that the inflammatory response in the wounds treated with $S$. thermophilus was less intense compared to the control groups, especially the vehicle controls. Previous research indicates that the bacteria may have some antiinflammatory effects (24-26). Moreover, the antibacterial properties of $S$. thermophilus against some opportunistic bacteria that may cause wound infection have been demonstrated (27). Infection of the wounds by fewer pathogens would cause a less intense inflammatory response, a situation observed in our experimental groups. If the inflammatory phase ends sooner, the proliferative phase will begin in a shorter time; therefore, the whole process of wound healing takes less time. In line with the microscopic results, on day 3 , the macroscopic results showed that the wound healing rate was significantly higher in the experimental group compared to the control groups. In the present study, the highest wound healing rate was observed in the experimental group on the seventh day of the experiments. On the same day, the rate of processes that occur in the proliferation phase of wound healing including fibroblasts migration, formation of collagen and reepithelialization was also highest in the experimental groups. On day 14, the collagen fibers arrangement in the experimental group was more regular than in other groups and had a nearly reticular pattern, which is indicative of normal skin in rodents (28).

On day 14 , the rate of wound healing in the experimental group was higher than both vehicle controls but not the negative control group. The vehicle controls received moisturizing ointment during the study period, which makes the wound area more suitable for the growth of opportunistic bacteria, such as Pseudomonas aeruginosa $(29,30)$. However, these effects were eliminated in the experimental groups due to the antibacterial properties of $S$. thermophilus (31). 
Another reason for the positive effects of $S$. thermophilus on the wound healing process is the production of ceramide (14), which can have healing effects on the wounds (15). Altogether, our results indicate the beneficial effects of spray-dried $S$. thermophilus on burn wound healing process. These results are in line with the results of other studies. For example, Peral et al. showed that topical use of Lactobacillus plantarum had positive effects on healing of second- and third-degree burn wounds (19). Moreover, administration of kefir grains that contain a mixture of probiotic bacteria on wounds can accelerate the healing process $(20,32)$.

$S$. thermophilus is generally regarded as safe since it lacks virulence-related genes $(33,34)$ and has been widely used in the dairy industry. Therefore, the topical use of these bacteria on skin may be also safe. Furthermore, spray drying is an affordable and simple method for preservation of viable bacteria.

The skin of rat is different from that of humans

\section{REFERENCES}

1. Roberts AH. Burn Prevention-where now? : Elsevier; 2000 .

2. Ahuja RB, Bhattacharya S. Burns in the developing world and burn disasters. BMJ. 2004; 329(7463): 447-9.

3. Settle JA. Principles and practice of burns management. Churchill Livingstone; 1996.

4. Barajas-Nava LA, Lopez-Alcalde J, Roqué i Figuls M, Solà I, Bonfill Cosp X. Antibiotic prophylaxis for preventing burn wound infection. status and date: New, published in. 2013(6).

5. Cho A-R. Effect of silver sulfadiazine on the skin cell proliferation and wound healing process in hairless mouse 2nd degree burn model. Journal of Pharmaceutical Investigation. 2002;32(2):113-7.

6. Percival S, Bowler P, Russell D. Bacterial resistance to silver in wound care. Journal of hospital infection. 2005; 60(1): 1-7.

7. Hossain MI, Sadekuzzaman M, Ha S-D. Probiotics as potential alternative biocontrol agents in the agriculture and food industries: A review. Food Research International. 2017; 100(Pt 1): 63-73. doi: 10.1016/j.foodres.

8. Araya M, Morelli L, Reid G, Sanders M, Stanton C, Pineiro M. Joint FAO/WHO Working Group report on drafting guidelines for the evaluation of probiotics in food. London, Canada: World Health Organization, Food and Agriculture Organization of the United Nations. 2002.

9. Yeşilova Y, Çalka Ö, Akdeniz N, Berktaş M. Effect of probiotics on the treatment of children with atopic dermatitis. Ann Dermatol. 2012; 24(2): 189-93. doi: 10.5021/ad.2012.24.2.189. both in terms of structure and function (35-38), and the healing process of a skin wound in the two species differs in some aspects (39). Therefore, more studies on animals with a more similar skin to that of humans or on volunteer patients are essential to confirm the positive effects of $S$. thermophilus on burn wound healing.

\section{CONCLUSION}

Our results indicate that the topical use of spray-dried S. thermophilus could be useful for the treatment of burn wounds.

\section{ACKNOWLEDGMENTS}

All animal experiments were carried out in the animal house of the University of Maragheh, Iran. We sincerely thank the Zisttakhmir Company for providing the spraydried S. thermophilus for our experiments.

\section{CONFLICT OF INTEREST}

We have no conflict of interest to declare.

10. Argenta A, Satish L, Gallo P, Liu F, Kathju S. Local application of probiotic bacteria prophylaxes against sepsis and death resulting from burn wound infection. PloS one. 2016;11(10):e0165294.

11. Sekhar MS, Unnikrishnan M, Vijayanarayana K, Rodrigues GS, Mukhopadhyay C. Topical application/formulation of probiotics: Will it be a novel treatment approach for diabetic foot ulcer? Medical hypotheses. 2014; 82(1): 86-8. doi: 10.1016/j.mehy.2013.11.013.

12. Drago L, Iemoli E, Rodighiero V, Nicola L, De Vecchi E, Piconi S. Effects of Lactobacillus salivarius LS01 (DSM 22775) treatment on adult atopic dermatitis: a randomized placebo-controlled study. International journal of immunopathology and pharmacology. 2011; 24(4): 1037-48. DOI:10.1177/039463201102400421.

13. Nole KLB, Yim E, Keri JE. Probiotics and prebiotics in dermatology. Journal of the American Academy of Dermatology. 2014;71(4):814-21. doi: 10.1016/j.jaad.2014.04.050.

14. Di Marzio L, Centi C, Cinque B, Masci S, Giuliani M, Arcieri A, et al. Effect of the lactic acid bacterium Streptococcus thermophilus on stratum corneum ceramide levels and signs and symptoms of atopic dermatitis patients. Experimental dermatology. 2003;12(5):615-20.

15. Tsuchiya S, Ichioka S, Sekiya N, Tajima S, Iwasaki $\mathrm{T}$, Numata S. The effect of a hydrocolloid dressing containing ceramide-2 on split-thickness wounds in a laser-induced erosion model. Adv Skin Wound Care. 2013; 26(5): 224-9. doi: 10.1097/01.ASW.0000428952.00149.77. 
16. Peighambardoust S, Tafti AG, Hesari J. Application of spray drying for preservation of lactic acid starter cultures: a review. Trends in Food Science \& Technology. 2011; 22(5): 215-24.

17. Silva J, Carvalho A, Teixeira P, Gibbs P. Bacteriocin production by spray-dried lactic acid bacteria. Letters in Applied Microbiology. 2002; 34(2): 77-81.

18. Mauriello G, Aponte M, Andolfi R, Moschetti G, Villani F. Spray-drying of bacteriocin-producing lactic acid bacteria. Journal of food protection. 1999; 62(7): 773-7.

19. Peral MC, Martinez MA, Valdez JC. Bacteriotherapy with Lactobacillus plantarum in burns. Int Wound $\mathrm{J}$. 2009; 6(1): 73-81. doi: 10.1111/j.1742481X.2008.00577.x.

20. Rodrigues KL, Caputo LRG, Carvalho JCT, Evangelista J, Schneedorf JM. Antimicrobial and healing activity of kefir and kefiran extract. Int $\mathbf{J}$ Antimicrob Agents. 2005; 25(5): 404-8.

21. Pereira T, Dos Santos D, Lima-Ribeiro MHM, de Pontes-Filho NT, Carneiro-Leão AMdA, Correia MTdS. Development of animal model for studying deep seconddegree thermal burns. BioMed Research International. 2012; http://dx.doi.org/10.1155/2012/460841.

22. Fish R, Danneman PJ, Brown M, Karas A. Anesthesia and analgesia in laboratory animals. $2^{\text {nd }}$ ed. Academic Press. 2008.

23. Gonzalez ACdO, Costa TF, Andrade ZdA, Medrado ARAP. Wound healing-A literature review. An Bras Dermatol. 2016; 91(5): 614-620. doi: 10.1590/abd18064841.20164741.

24. Della Riccia D, Bizzini F, Perilli M, Polimeni A, Trinchieri V, Amicosante G, et al. Anti-inflammatory effects of Lactobacillus brevis (CD2) on periodontal disease. Oral Diseases. 2007;13(4):376-85. DOI:10.1111/j.1601-0825.2006.01291.x.

25. von Schillde M-A, Hörmannsperger G, Weiher M, Alpert C-A, Hahne H, Bäuerl C, et al. Lactocepin secreted by Lactobacillus exerts anti-inflammatory effects by selectively degrading proinflammatory chemokines. Cell host \& microbe. 2012; 11(4): 387-96. doi: 10.1016/j.chom.2012.02.006.

26. Kekkonen RA, Lummela N, Karjalainen H, Latvala S, Tynkkynen S, Järvenpää S, et al. Probiotic intervention has strain-specific anti-inflammatory effects in healthy adults. World J Gastroenterol. 2008; 14(13): 2029-36.

27. Fang W, Shi M, Huang L, Chen J, Wang Y. Antagonism of lactic acid bacteria towards Staphylococcus aureus and Escherichia coli on agar plates and in milk. Veterinary research. 1996; 27(1): 312.
28. Xue M, Jackson CJ. Extracellular matrix reorganization during wound healing and its impact on abnormal scarring. Adv Wound Care (New Rochelle). 2015;4(3):119-136.

29. Tredget EE, Shankowsky HA, Joffe AM, Inkson TI, Volpel K, Paranchych W, et al. Epidemiology of infections with Pseudomonas aeruginosa in burn patients: the role of hydrotherapy. Clinical Infectious Diseases. 1992; 15(6): 941-9.

30. Lari AR, Alaghehbandan R, Akhlaghi L. Burn wound infections and antimicrobial resistance in Tehran, Iran: an increasing problem. Ann Burns Fire Disasters. 2005;18(2):68.

31. Klaenhammer TR. Bacteriocins of lactic acid bacteria. Biochimie. 1988; 70(3): 337-49.

32. Huseini HF, Rahimzadeh G, Fazeli MR, Mehrazma M, Salehi M. Evaluation of wound healing activities of kefir products. Burns. 2012;38(5):719-23.

33. Delorme C. Safety assessment of dairy microorganisms: Streptococcus thermophilus. Int J Food Microbiol. 2008; 274-7. DOI:10.1016/j.ijfoodmicro.2007.08.014.

34. Bolotin A, Quinquis B, Renault P, Sorokin A, Ehrlich $\mathrm{SD}$, Kulakauskas $\mathrm{S}$, et al. Complete sequence and comparative genome analysis of the dairy bacterium Streptococcus thermophilus. Nature biotechnology. 2004; 22(12): 1554-8.

35. Bartek MJ, Labudde JA, Maibach HI. Skin permeability in vivo: comparison in rat, rabbit, pig and man. J Invest Dermatol. 1972; 58(3): 114-23.

36. Barber ED, Teetsel NM, Kolberg KF, Guest D. A comparative study of the rates of in vitro percutaneous absorption of eight chemicals using rat and human skin. Fundamental and Applied Toxicology. 1992; 19(4): 4937.

37. Van Ravenzwaay B, Leibold E. A comparison between in vitro rat and human and in vivo rat skin absorption studies. Hum Exp Toxicol. 2004; 23(9): 42130.

38. Dorsett-Martin WA. Rat models of skin wound healing: a review. Wound Repair Regen. 2004;12(6):591-9.

39. Gottrup F, Ågren MS, Karlsmark T. Models for use in wound healing research: a survey focusing on in vitro and in vivo adult soft tissue. Wound Repair and Regeneration. 2000;8(2):83-96. 